\title{
Echinococcus multilocularis metacestode metabolites contain a cysteine protease that digests eotaxin, a CC pro-inflammatory chemokine
}

\author{
N. Mejri • B. Gottstein
}

Received: 16 June 2009 / Accepted: 19 June 2009 / Published online: 2 July 2009

(C) Springer-Verlag 2009

\begin{abstract}
In many helminthic infections, eotaxin, a CCchemokine, triggers the mobilization of eosinophils, thus, contributing to an elevated blood and periparasitic eosinophil level. Following an experimental intraperitoneal infection of C57BL6 mice with Echinococcus multilocularis metacestodes, however, we observed the absence of eosinophils in the peritoneal cavity and a low number of such cells in the blood of infected animals. Therefore, we carried out an explorative study to address the question why eosinophilia did not occur especially in the peritoneal cavity of such secondarily AE-infected mice. In an in vitro assay, we showed that metacestode antigens (in vitro generated vesicle fluid and $\mathrm{E} / \mathrm{S}$ products) were able to proteolytically digest eotaxin. This effect was confirmed with semiquantitative Western blotting, which demonstrated a decreasing intensity of remaining eotaxin signals. Proteolysis of eotaxin was, thus, dose-dependent and proportional to the time of incubation with the metacestode antigens. Using appropriate inhibitors, the respective protease was identified as a cysteine protease, which required the presence of $\mathrm{Ca}^{++}$as co-enzyme. A chromatographic fractionation procedure by successive separation of VF molecules using a superpose column and subsequently a MonoQ column mounted on an FPLC system allowed to yield a fraction, referred to us as fraction 6; containing the enriched cysteine protease, this fraction will be used for further molecular studies. Eotaxin inactivation by VF and E/S products may contribute to explain the absence of eosinophils within the peritoneal cavity of AE-secondary infected mice. Absent
\end{abstract}

This work was funded by the Swiss National Research Foundation (grant no. 31003A-125990/1).

N. Mejri • B. Gottstein $(\bowtie)$

Institute of Parasitology, University of Berne,

Länggass-Strasse 122,

3012 Bern, Switzerland

e-mail: bruno.gottstein@ipa.unibe.ch eosinophils, thus, may be a part of a series of events that maintain a low level of inflammation displayed within the peritoneal cavity of experimentally infected mice.

\section{Introduction}

Alveolar echinococcosis (AE) is caused by infection of intermediate hosts (predominantly rodents, accidentally humans) with the metacestode or the larval stage of the fox tapeworm Echinococcus multilocularis. AE is one of the most lethal helminthic infections in humans. The metacestode develops mainly in the liver in form of a tumor-like, vesiculated, and vascularized tissue. Subsequently, metastasis may be formed at other sites such as in the peritoneum, the diaphragm, the lungs, the spleen, and the kidney, among other sites (Gottstein and Hemphill 2008).

So far, little is known on E/S products or other structural molecules acting on, or interfering with, the host immune system. A number of molecules have been identified within the laminated layer of E. multilocularis metacestodes. These include the T-cell independent Em2 antigen (Dai et al. 2001), EmAP (Lawton et al. 1997), EmP2 (Ingold et al. 1998), antigen C (Sato and Furuya 1994), Em492 antigen (Walker et al. 2004), and high molecular mass glycans which form the major structural elements (Ingold et al. 2000). The studies also showed that Em2 and Em492 antigens represent constituents of the E/S fraction of intact metacestodes (Hemphill and Gottstein 1995), while Em492 also exhibited the potential involvement in modulating the host-parasite interface (Walker et al. 2004). Several recombinant $E$. multilocularis antigens, such as recII/3-10 (Muller et al. 1989), recEm18 (Ito et al. 1995), and recEM10 (Frosch et al. 1991; all belonging to the same family of EMR proteins) were primarily identified and expressed in view of their immunodiagnostic potential and not of their potential 
biological function. Functionally interesting parasite molecules were few to be identified so far, including the 14-3-3 protein, which appeared to contribute to the tumor-like growth capacity of the parasite germinal tissue (Siles-Lucas Mdel and Gottstein 2003). In murine infections with $E$. multilocularis, the involvement of cellular immunity in controlling the infection is strongly suggested by the intense granulomatous infiltration observed in the periparasitic area of lesions (Bresson-Hadni et al. 1990; Emery et al. 1996; Vuitton et al. 1989). Based on in vitro and in vivo studies, Th2-dominated immunity was more associated with increased susceptibility to AE disease (Emery et al. 1996). Moreover, some immunosuppressive mechanisms were described to be favorable for the establishment of AE. A high periparasitic NO production by peritoneal exudate cells contributed to periparasitic immunosuppression (Dai and Gottstein 1999). A marked depression of the cell-mediated immune response has been observed in chronic AE (Devouge and Ali-Khan 1983; Kizaki et al. 1991). Antigen-presenting cells (APCs) such as macrophages from infected mice (AE-MØ) exhibited a reduced ability to present a conventional antigen (chicken ovalbumin, C-Ova) to specific responder lymph node $\mathrm{T}$ cells when compared to normal MØ (Mejri and Gottstein 2006). It became also clear that metacestode components, either constitutively expressed on the parasite surface or metabolized, are involved in modulating the host-parasite interface (see above). In this context, Aumüller et al. (2004) used metacestode extracts to induce in vitro basophil degranulation, as well as the secretion of histamine, IL-4 and IL-13.

In the present work, we specifically addressed the question whether bioactive metabolites, especially proteases, may be involved in immunomodulary mechanisms, focusing on the phenomenon of lacking eosinophilia during murine AE. We hereby investigated whether metacestode antigens (VF and E/S) exhibit proteolytic activity on eotaxin, a CC-proinflammatory chemokine, in vitro. An inhibition of eotaxin activity may suppress the mobilization of eosinophils into the peritoneal cavity of intraperitoneally AE-infected mice. Eotaxin is considered as one of the main activator and chemo-attractant of resident eosinophils secreted principally by epithelial cells of the intestine (Mishra et al. 2002). A putative inhibition of granulocytic eosinophil infiltration may be relevant for parasite survival, as this type of cells is particularly important in the defense against helminthes (Ovington and Behm 1997; Burden et al. 1983).

\section{Materials and methods}

Mice

Female 6-10 week-old C57BL/6 mice were purchased from Charles River Lab (Germany) and used for intraperitoneal infection with E. multilocularis metacestodes or as noninfected control mice. All mice were raised, housed, and handled according to the rules of the Swiss regulations for animal experimentation.

Parasite, experimental infection

The parasite used in this study was a cloned E. multilocularis (KF5) isolate maintained by serial passages (vegetative transfer) in C57BL/6 mice (Gottstein 1992). Metacestode tissue was obtained from infected mice by aseptic removal from the peritoneal cavity. After grinding the tissue through a sterile thieve $(50 \mu \mathrm{m}$ mesh diameter), 50 to 100 freshly prepared acephalic vesicular cysts were suspended in $100 \mu \mathrm{l}$ RPMI-1640 (Gibco, Basel, Switzerland) and injected intraperitoneally into a mouse for secondary infection. Control mice received $100 \mu \mathrm{l}$ of RPMI-1640 only. Each experimental group included five animals.

\section{Preparation of blood smear and peritoneal leukocytes}

Blood from infected and naïve mice was recovered in heparinated tube and used for the preparation of blood smears by spreading a drop of blood thinly over a microscope slide, a subsequent staining was performed according to the Pappenheim method (May-Günwald/Giemsa).

Peritoneal cavities of naïve and AE-infected mice were washed with sterile PBS, and from the recovered cell suspension, a concentration of $10^{6}$ cells was prepared from the two groups of mice each. From each suspension, three samples of $10^{5}$ cells $/ 100 \mu$ l were loaded into cytospins cups, and cells were allowed to adhere on the microscope slides using sedimentation at $800 \times \mathrm{g}$ for $5 \mathrm{~min}$.

\section{Metacestode antigens}

Metacestode vesicles were obtained from an in vitro culture system as previously described by (Hemphill and Gottstein 1995). For a final step, vesicles were washed three times and subsequently kept in pure RPMI-1640 for $48 \mathrm{~h}$. The supernatant containing the excreted and secreted metabolites (E/S) was collected and stored at $-80^{\circ} \mathrm{C}$ until use. Vesicle fluid (VF) was aseptically aspirated with a syringe and a $27 \mathrm{G}$ needle from single metacestode vesicles, VF was stored in aliquots at $-80^{\circ} \mathrm{C}$ until use.

Determination of proteolytic activity

A constant quantity of $50 \mathrm{ng}$ eotaxin (Cat no: PMC 1435, Biosource, Switzerland) was incubated (as a substrate) in PBS plus $\mathrm{CaCl}_{2}(1 \mathrm{mM})$ with increasing quantities of $\mathrm{VF}$ 
and $\mathrm{E} / \mathrm{S}$ products, ranging from 0.5 to 2 and 0.05 to $0.4 \mu \mathrm{g}$ (protein), respectively, for $1 \mathrm{~h}$ and $15 \mathrm{~min}$ at $37^{\circ} \mathrm{C}$.

To study the time course of the eotaxin proteolysis, $50 \mathrm{ng}$ of eotaxin was incubated separately with a constant quantity of VF $(1.5 \mu \mathrm{g})$ and $\mathrm{E} / \mathrm{S}$ products $(0.15 \mu \mathrm{g})$ in PBS, $\mathrm{CaCl} 21 \mathrm{mM}$ for different time periods $(0,15,30$, and $60 \mathrm{~min}$ ) at $37^{\circ} \mathrm{C}$. Proteolytic effect on eotaxin was assessed by determining the signals of the remaining eotaxin by semiquantitative Western blotting.

Proteolytic reactions were stopped by adding an appropriate volume of loading buffer (Gottstein et al. 1986) and immediate boiling for $5 \mathrm{~min}$. Samples were resolved on a 20\% SDS-PAGE gel under standard reducing conditions (Laemmli 1970). Proteins were transferred onto sequencing grade polyvinylidene difluoride membranes in $25 \%$ methanol, $25 \mathrm{mM}$ Tris base, $200 \mathrm{~mm}$ glycine, and $1.7 \mathrm{mM}$ SDS at $\mathrm{pH} 8.3$ for $40 \mathrm{~min}$ (Culley et al. 2000). Membranes were subsequently blocked with $5 \%$ fat-free milk powder in PBS for $30 \mathrm{~min}$, followed by incubation overnight at $4^{\circ} \mathrm{C}$ with a primary rat antimurine eotaxin antibody (Cat no: E4150, Sigma, Switzerland) at $1.5 \mu \mathrm{g} / \mathrm{ml}$ in $1 \%$ milk powder in PBS. Membranes were washed $3 \times 10 \mathrm{~min}$ in PBS followed by detection with goat anti-rat alkaline phosphataseconjugated secondary antibody at $1: 1,000$ in $1 \%$ milk powder in PBS for $1 \mathrm{~h}$ at room temperature.

Determination of protease class

To determine the class of protease that digested eotaxin, we used PMSF, E-64, pepstatin, and phenanthroline (Sigma, Switzerland) as inhibitors of the four classes of protease, serine, cysteine, aspartic, and metallo-protease, respectively. A constant quantity of VF $(5 \mu \mathrm{g})$ and $\mathrm{E} / \mathrm{S}(12 \mu \mathrm{g})$ products were preincubated with different protease inhibitors at working concentrations for PMSF $(1 \mathrm{mM})$, E-64 $(0.02 \mathrm{mM})$, pepstatin $(0.1 \mathrm{mM})$, and phenanthroline $(0.5 \mathrm{mM})$ during $1 \mathrm{~h}$ before adding $50 \mathrm{ng}$ of eotaxin. The enzymatic reactions were maintained for $1 \mathrm{~h}$ and $15 \mathrm{~min}$ at $37^{\circ} \mathrm{C}$.

To investigate whether the proteolytic activity of VF and $\mathrm{E} / \mathrm{S}$ on eotaxin was $\mathrm{Ca}^{++}$-dependent, E. multilocularis antigens were incubated with eotaxin in PBS containing separately $\mathrm{CaCl}_{2}, \mathrm{ZnCl}_{2}$, and $\mathrm{MgCl}_{2}$ each at the concentration of $1 \mathrm{mM}$. To inhibit the co-enzyme activity of the calcium, EGTA as a calcium chelator was added to the enzymatic reaction at a concentration of $2 \mathrm{mM}$.

\section{Chromatographic fractionation of VF}

A two-step approach was used to separate VF molecules into different chromatographic fractions. VF that was dialyzed against PBS $10 \mathrm{mM}$ at $\mathrm{pH} 7.5$ and sterilized through $0.22-\mu \mathrm{m}$ filter was first fractionated upon molec- ular mass by fast performance liquid chromatography (FPLC) using a Superose column (Pharmacia, Switzerland). Each fraction was separately assayed for its proteolytic activity on eotaxin. SDS-PAGE analysis of active fractions showed a complex profile (not published), thus, suggesting to carry out a second round of chromatography. Based on separation by anion exchange, we employed a MonoQ HR $5 / 5$ column (Pharmacia, Switzerland) for further fractionation of a pool containing all proteolytic fractions previously eluted from superpose column. Proteolitically active fractions from the second separation were determined as in the first fractionation by separate co-incubation of $50 \mathrm{ng}$ of eotaxin substrate in PBS plus $\mathrm{CaCl}_{2}(1 \mathrm{mM})$ with $16 \mu$ of each chromatographic fraction for $1 \mathrm{~h}$ and $15 \mathrm{~min}$ at $37^{\circ} \mathrm{C}$. The detection of eotaxin signals was performed by semiquantitative Western blot as outlined above.

\section{Results}

Proteolytic effect of VF and E/S products on eotaxin

As shown in Fig. 1a, following incubation of increasing doses of both $\mathrm{E} / \mathrm{S}$ and VF metabolites with eotaxin as a substrate, a degrading profile was obtained, illustrated by the decreasing signal of remaining eotaxin upon detection with an anti-eotaxin antibody by Western blot. Protein concentrations as low as $0.4 \mu \mathrm{g}$ of $\mathrm{E} / \mathrm{S}$ and $2 \mu \mathrm{g}$ of VF were needed to obtain the faintest signal of eotaxin. This finding indicated that both the $\mathrm{E} / \mathrm{S}$ products and VF metabolites contained, respectively, active proteases that digested eotaxin.

Time course of proteolysis

We examined the rate of enzyme activity, as a function of time, of the E. multilocularis metacestodes $\mathrm{E} / \mathrm{S} \mathrm{VF}$ antigens. Following incubation of $50 \mathrm{ng}$ of eotaxin with a constant quantity of E/S products and VF at different time points, the time course of eotaxin digestion was assessed by Western blotting that illustrated a reduction of the signal in proportion to reducing amounts of eotaxin substrate. As shown in Fig. 1b, increasing incubation time correlated with decreasing intensity of the remaining eotaxin signal.

Determination of the nature of the proteolytic enzyme

To preliminarily classify the protease, the eotaxin substrate was incubated separately with a constant quantity of $E$. multilocularis metacestodes $\mathrm{VF}$ and $\mathrm{E} / \mathrm{S}$ products treated with individual protease inhibitors (PMSF, E-64, pepstatin, and phenanthroline). Inhibitors were omitted in the appropriate enzymatic control reaction. In comparison to this 

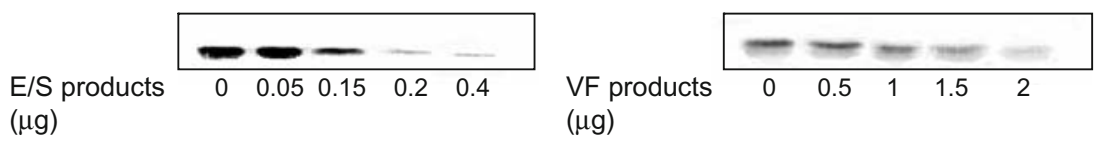

(a)

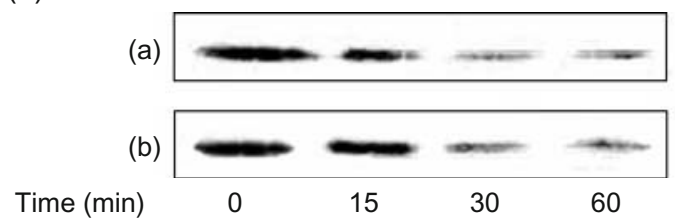

(b)

Fig. 1 Proteolytic effect of E/S products and VF on the eotaxin substrate. Western-blot revealed decreasing signals of the remaining eotaxin following incubation with increasing indicated amounts of a

control, a similarly intense signal of eotaxin was detected when it was incubated with VF and E/S treated with E-64 a cysteine protease inhibitor. The other protease inhibitors (PMSF, pepstatin, and phenanthroline) did not interfere in the proteolysis of the eotaxin, as illustrated in Fig. 2 by the relatively reduced signals of eotaxin. Thus, the protease was revealed to belong to the class of cysteine proteases.

$\mathrm{Ca}^{++}$dependency of the proteolytic activity

The metal ion required as co-enzyme in the proteolysis of eotaxin by $\mathrm{VF}$ or $\mathrm{E} / \mathrm{S}$ products was investigated by selective addition of $\mathrm{Ca}^{++}, \mathrm{Mg}^{++}$, and $\mathrm{Mn}^{++}$into the enzymatic reaction. As shown in Fig. 3a, calcium $\left(\mathrm{Ca}^{++}\right)$ activated proteolysis of eotaxin, while magnesium $\left(\mathrm{Mg}^{++}\right)$ and manganese $\left(\mathrm{Mn}^{++}\right)$had no effect on the proteolytic activity. In comparison with the control (in the absence of the metal ions), a reduced signal of eotaxin was detected only in the presence of $\mathrm{Ca}^{++}$, while practically similar signal intensities appeared in the presence of $\mathrm{Mg}^{++}$and $\mathrm{Mn}^{++}$. Thus, the $\mathrm{Ca}^{++}$ion is required as co-enzyme for the activation of the cysteine protease produced by E. multilocalaris metacestodes to digest the eotaxin.

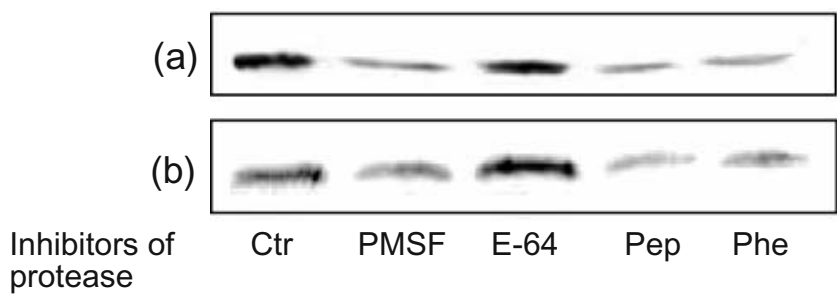

Fig. 2 The inhibitory effect of E-64 (an inhibitor of cysteine protease) on the proteolytic activity of $\mathbf{a} \mathrm{E} / \mathrm{S}$ products and $\mathbf{b} \mathrm{VF}$ on the eotaxin substrate. Reduced signals of eotaxin were observed following incubation with $\mathrm{E} / \mathrm{S}$ or VF antigens pretreated with PMSF, pepstatin, and phenanthroline separately while a practically similar signal was detected in the presence E-64 in comparison with the control when the eotaxin was blotted alone. The eotaxin proteolysis was triggered by a cysteine protease
E/S and b VF products. Decreasing signals illustrated also the increasing proteolytic effect of $\mathrm{E} / \mathrm{S}$ products and $\mathrm{VF}$ on the eotaxin substrate during the time

EGTA selectively chelates calcium. EGTA treatment of $\mathrm{VF}$ and $\mathrm{E} / \mathrm{S}$ reduced their proteolytic activity. In comparison with the positive control (in absence of EGTA), the eotaxin signals were more intense when $\mathrm{VF}$ and $\mathrm{E} / \mathrm{S}$ were treated with EGTA (Fig. 3b). The difference appeared more pronounced with VF treatment, which indicated that VF could contain endogenous $\mathrm{Ca}^{++}$. This finding confirmed that the cysteine protease activity is calcium-sensitive.

Protease enriched chromatographic fractionation using FPLC

The screening for proteolytic activity of chromatographic fractions that emerged from a separation using a superpose column showed that the eotaxin substrate was digested by fractions 11, 12, and 13 (Fig. 4), with fraction 11 exhibiting the highest effect. In the elution profile, the curve that included proteolytic fractions 11,12 , and 13 was relatively large, indicating a still rather complex molecular composition. Consequently, fractions 11,12 , and 13 were pooled and subsequently subject to a second round of chromatography using a Mono-Q column. The analysis of, respectively, recovered fractions for their proteolytic activity showed that the new fractions 5, 6, and 7 digested the eotaxin (Fig. 5). The highest proteolytic activity was obtained with fraction 6 (Fig. 5b). This fraction 6 will be used in future studies to identify and clone the parasite gene encoding for this protease.

\section{Discussion}

Most experimental studies with E. multilocularis have been carried out so far in laboratory rodents such as gerbils and mice infected via intraperitoneal inoculation of metacestode vesicles referred to as secondary infection. In infected C57BL/6 mice, the growth of the parasite and the evolution of the disease into its chronic phase strongly evoke the 


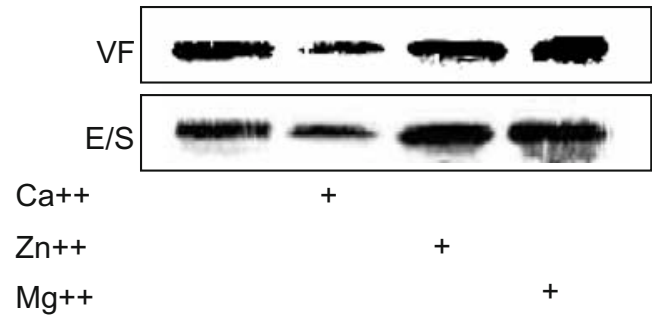

(a)

Fig. 3 The proteolytic activities of E/S products and of VF on the eotaxin substrate are $\mathrm{Ca}^{++}$dependent. a The selective addition of $\mathrm{Zn}^{++}$ and $\mathrm{Mg}^{++}$in the medium when eotaxin was incubated with $\mathrm{E} / \mathrm{S}$ or $\mathrm{VF}$ did not trigger any proteolysis of the eotaxin as indicated by the similar intensity of the signals as the control when the eotaxin was

presence of immunomodulatory events orchestrated by the parasite to reduce periparasitic host effector mechanisms and, thus, to increase the survival potential of the parasite. Most likely, these immunomodulatory activities involve metabolically active molecules expressed by the germinal layer of the metacestode and secreted through the laminated layer into the periparasitic environment. The laminated layer itself completely surrounds the metacestode to provide protection against host effector mecha-

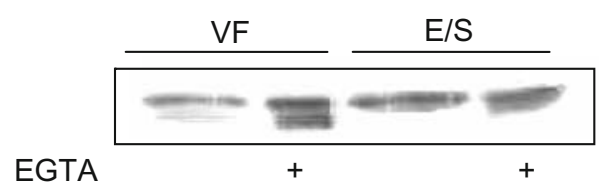

(b)

blotted alone. While $\mathrm{Ca}^{++}$added to the medium activated the protease contained in the $\mathrm{VF}$ and $\mathrm{E} / \mathrm{S}$ to digest the eotaxin triggering a reduction of their signal. b This protease activation was inhibited when $\mathrm{Ca}^{++}$was chelated with EGTA, as revealed by the high eotaxin signal

nisms. Furthermore, it acts also as the unique site of metabolic transfer (Gottstein and Hemphill 1997). It has been demonstrated that E. multilocularis secretes molecules that manipulate the immune system by modifying their function; thus, a depletion of T cells was shown to occur in the paracortex of local lymph nodes (Ali-Khan and Siboo 1980), or a reduction of the percentage of CD8+ T cells in PBMC of AE patients was shown to contribute to the tolerance of the parasite (Vuitton et al. 1989). An increased nitric oxide production
Fig. 4 a Elution profile of the vesicle fluid of $E$. mutilocularis metacestodes from the superpose column connected to the FPLC system. The fractions were harvested each in $0.5 \mathrm{ml}$ of PBS b. The peak area indicated by the arrow, corresponds to the fractions 11,12 , and 13 containing molecules with proteolytic activity on eotaxin substrate as shown in (b) by the reduced signal of remaining eotaxin detected by Western blot

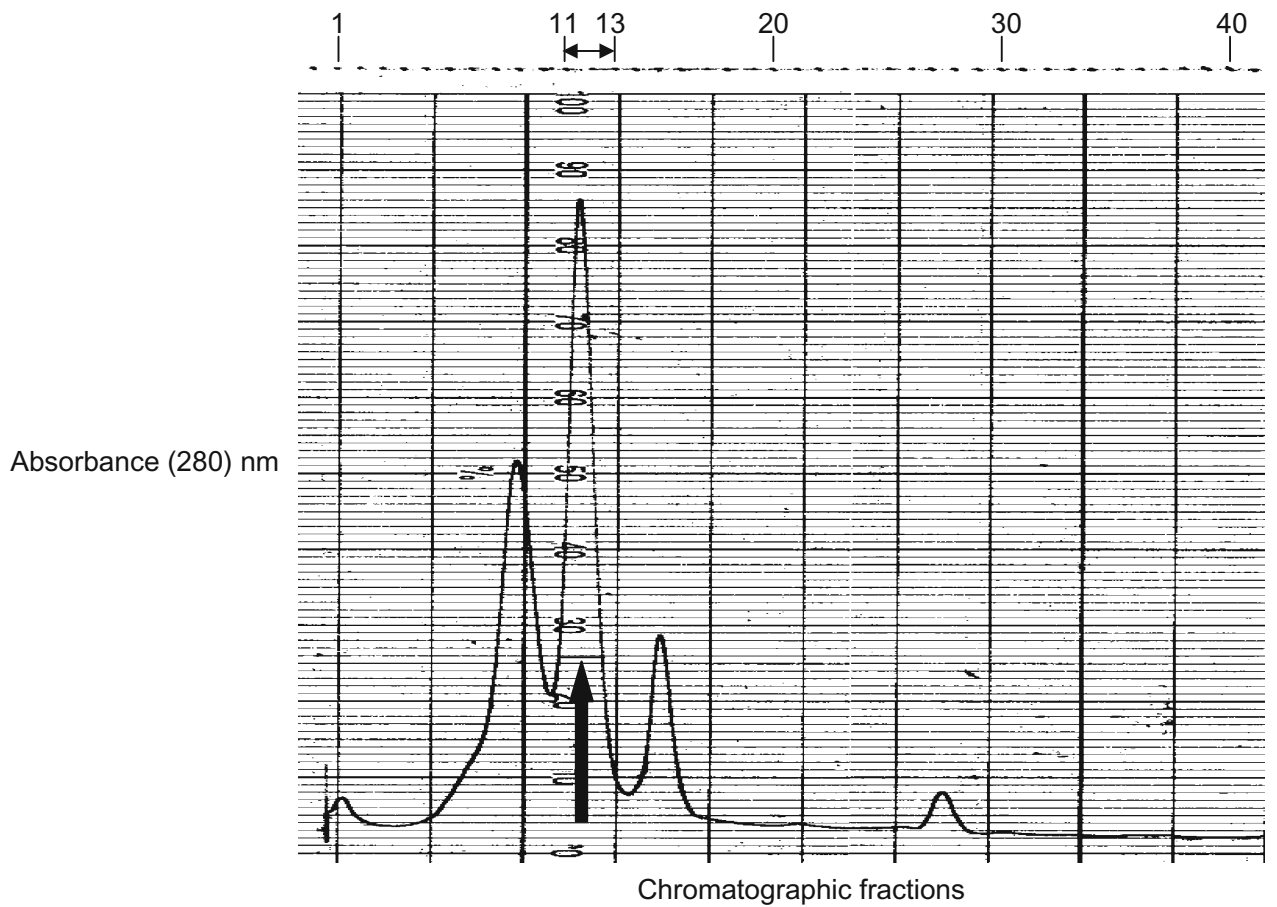

(a)

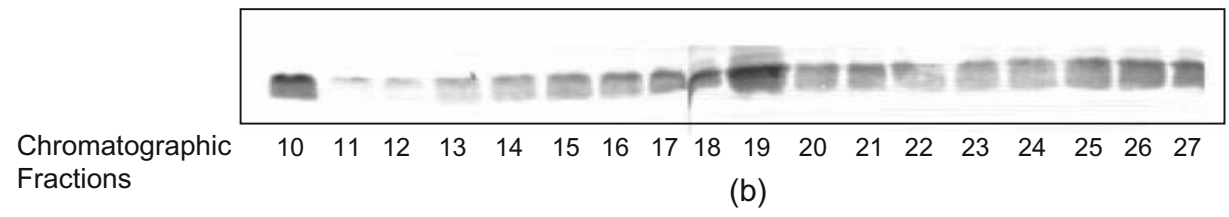


Fig. 5 a Elution profile of a pool of fractions 11, 12, and 13 from anion exchange chromatography. A linear increasing gradient of $\mathrm{NaCl}(50-600 \mathrm{mM})$ was used to generate fractions $10 \mathrm{mM}$ tris-buffer $\mathrm{pH}$ 7.5. The salt concentration change was $25 \mathrm{mM} / \mathrm{ml}$. using a total volume of $20 \mathrm{ml}$ for this gradient, the volume of each fraction was fixed at $0.5 \mathrm{ml}$. The arrow indicates the area corresponding to the fractions 5,6 , and 7 containing the molecules with proteolytic effect on the eotaxin substrate as shown in (b) by the reduced signal of the remaining eotaxin detected by Western blot

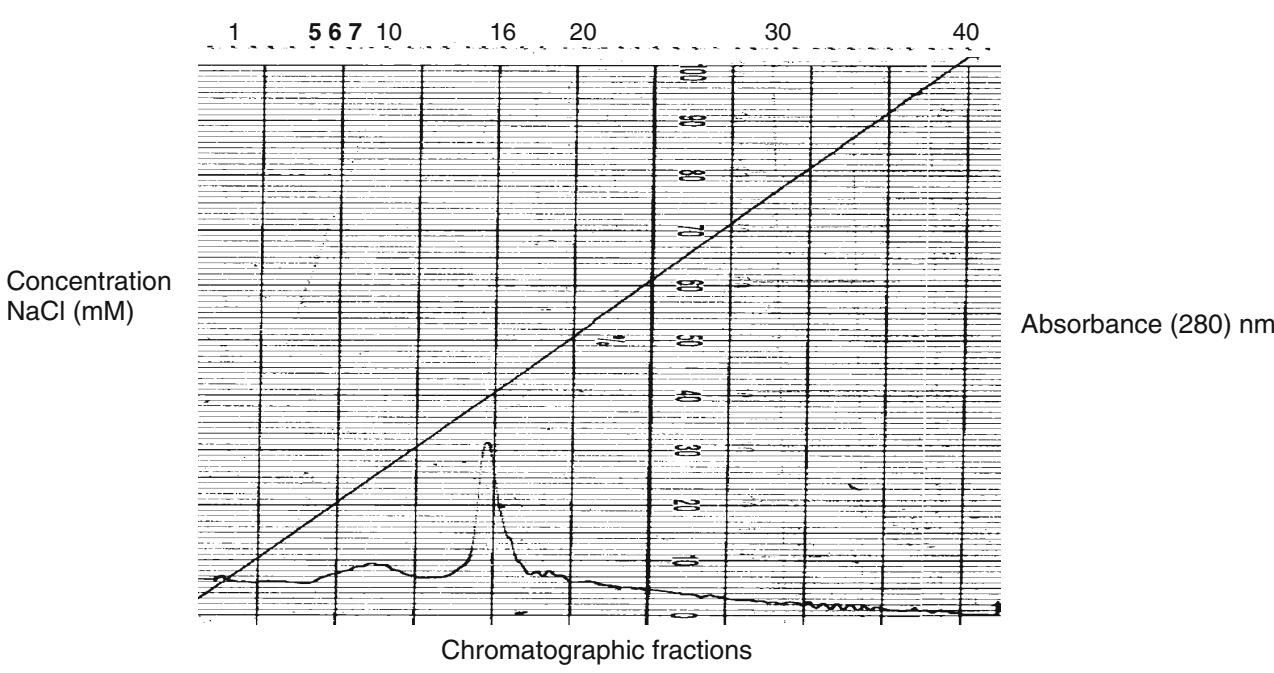

(a)

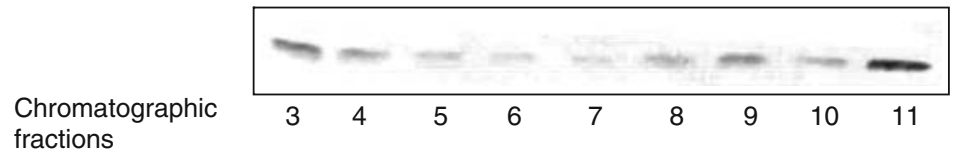

(b) has also been shown to suppress T-cell activities (Dai and Gottstein 1999; Dai et al. 2003). Previously, we showed also impairment in accessory activity of infiltrating macrophages (Mejri and Gottstein 2006) which represent the mean intraperitoneal APCs implicated in the development of the anti-E. multilocularis immune response.

In the context of the host-parasite interplay, we addressed the question whether E. multilocularis metacestodes release proteolytic metabolites that play a role in the survival strategy of the parasite. Basically, using gelatine zymography, we had demonstrated in a preparative investigation that $\mathrm{VF}$ and $\mathrm{E} / \mathrm{S}$ products contain proteases (data not published). In parallel, while assessing the overall leukocyte composition in experimentally infected mice, we found that eosinophils represented approximately $7 \%$ of murine leukocytes isolated from the blood, while eosinophils were virtually absent among peritoneal leukocytes of AE-infected mice. This was the clue that prompts us to investigate whether parasitic proteases interfere in eosinophil infiltration into the peritoneal cavity of AE-infected mice. We hypothesized that the parasite releases metabolic molecules, especially proteases that inhibit the activity of eotaxin, a chemokine that may mobilize and trigger the infiltration of eosinophils from the intestinal tissue into the peritoneal cavity of AE-infected mice. To check this hypothesis, we studied in vitro the proteolytic activity of metacestode E. multilocularis antigens ( VF and E/S product) on eotaxin as a respective substrate. Results revealed that $\mathrm{VF}$ as well as E/S products actually contained proteases that digest and thus inactivate eotaxin. This finding may contribute to the explanation why, conversely to many other helminthic infections, in AE the infiltration and attraction of eosinophils to the site of infection in the peritoneal cavity does not occur.

The mobilization of eosinophils is generally accepted to be a crucial immunological event playing an important role in host defense against helminthes. Eotaxin is not the unique chemo-attractant for eosinophils; IL-5 may also mobilize these cells (Yamaguchi et al. 1988), but its role remains controversial. In many examples of nematode infections, eosinophilia is a marked characteristic, and eosinophils can directly cause a profound damage to the tegument of the worms, such as Strongyloides ratti and Trichinella spiralis reducing their fertility and longevity (Machado et al. 2005), while IL-5 and eosinophils had no detectable effect on infection with Mesocestoides corti, Hymenolepis diminuta, and Fasciola hepatica (Ovington and Behm 1997). An extravasation of eosinophils causing eosinophilia in the peritoneal cavity has been demonstrated to be beneficial for the host by causing damage to the immigrant immature worm of $F$. hepatica, resulting to the erosion of the tegumental syncytium (Burden et al. 1983; Davies and Goose 1981). Eosinophils possess granules containing a variety of toxic molecules (major basic protein, peroxidase, neurotoxin, histaminase, and others) which are described to be efficient against many multicellular parasites, in particular helminthic parasites (Saraswathi et al. 2003; Martin et al. 1996).

The presence of IL-5 is not imperious to mobilize eosinophils because this cytokine belongs to a family of cytokines that shares a part of their molecular structure and functionality, with other cytokines such as IL-4 and IL-13. These two latter cytokines are known to trigger an extravasa- 
tion of eosinophils by upregulating ICAM-1 (Berger et al. 2002). In our model, the infection takes place within the peritoneal cavity; therefore, it is important to mention the presence of resident eosinophils in the intestinal tissue. If IL-5 predominantly stimulates the release of eosinophils from the bone marrow into the peripheral circulation, eotaxin, in our experimental model, predominantly mobilizes these cells from the intestine. Moreover, eotaxin is constitutively produced by mononuclear cells within the lamina propria of the mouse lower small intestine (Mishra et al. 1999; 2002). A relatively slight increase of IL-5 mRNA expression had been demonstrated in splenocytes of AE-secondary infected mice (Dai et al. 2001). Such a presence of IL-5 may help to explain, at least partially, the relatively elevated number of eosinophils preliminarily registered in the blood of AE-infected mice when compared with naïve control mice. Consequently, the absence of eosinophils in the peritoneal cavity could result from an in situ deactivation of eotaxin by parasite metabolites (E/S products), thus, contributing to the silencing of intraperitoneal periparasitic inflammatory reactions in the infected host. Indeed many authors already described a restricted inflammation following infection with $E$. multilocularis parasite, by revealing reduced levels of pro-inflammatory IL-1beta, IL-18, and IL-12 cytokines expression in human AE patients (Eger et al. 2003; Hubner et al. 2006).

In the present study, the cysteine protease contained in $\mathrm{VF}$ and $\mathrm{E} / \mathrm{S}$ products affects the eotaxin inhibiting its chemo-attractant activity. This mechanism illustrates the multifacet of the immune suppression occurred within secondary AE-infected mice. Previously, other metabolites such as E. multilocularis glycoprotein, named Em492, were found to be able to inhibit Con-A-driven splenocytes proliferation (Walker et al. 2004). Another neutral glycosphingolipid has been identified as suppressor of human PBMCs proliferation following stimulation by phytohemagglutinin (Persat et al. 1996). Several molecules from Echinococcus spp. have been attributed biological activities, including antigenicity (Hernandez and Nieto 1994; Sterla et al. 1999; Dai et al. 2001) and inhibition of cellular proliferation (Terrazas et al. 2001).

The presence of this cysteine protease in E. multilocularis metabolites definitely deserves further attention and molecular and cellular investigations. Preliminary chromatographic enrichment by FPLC yielded a highly proteolytic fraction referred to us as fraction 6, which can be used for further molecular characterization and subsequent identification of the gene encoding this bioactive molecule.

\section{Reference}

Ali-Khan Z, Siboo R (1980) Pathogenesis and host response in subcutaneous alveolar hydatidosis. II. Intense plasmacellular infiltration in the paracortex of draining lymph nodes. $\mathrm{Z}$ Parasitenkd 62:255-265

Aumüller E, Schramm G, Gronow A, Brehm K, Gibbs BF, Doenhoff MJ, Haas H (2004) Echinococcus multilocularis metacestode extract triggers human basophils to release interleukin-4. Parasite Immunol 26:387-395

Berger RB, Blackwell NM, Lass JH, Diaconu E, Pearlman E (2002) IL-4 and IL-13 regulation of ICAM-1 expression and eosinophil recruitment in Onchocerca volvulus keratitis. Invest Ophthalmol Vis Sci 43:2992-2997

Bresson-Hadni S, Liance M, Meyer JP, Houin R, Bresson JL, Vuitton DA (1990) Cellular immunity in experimental Echinococcus multilocularis infection. II. Sequential and comparative phenotypic study of the periparasitic mononuclear cells in resistant and sensitive mice. Clin Exp Immunol 82:378-383

Burden DJ, Bland AP, Hammet NC, Hughes DL (1983) Fasciola hepatica: migration of newly excysted juveniles in resistant rats. Exp Parasitol 56:277-288

Culley FJ, Brown A, Conroy DM, Sabroe I, Pritchard DI, Williams TJ (2000) Eotaxin is specifically cleaved by hookworm metalloproteases preventing its action in vitro and in vivo. J Immunol 165:6447-6453

Dai WJ, Gottstein B (1999) Nitric oxide-mediated immunosuppression following murine Echinococcus multilocularis infection. Immunology 97:107-116

Dai WJ, Hemphill A, Waldvogel A, Ingold K, Deplazes P, Mossmann H, Gottstein B (2001) Major carbohydrate antigen of Echinococcus multilocularis induces an immunoglobulin $\mathrm{G}$ response independent of alphabeta+CD4+ T cells. Infect Immun 69:6074-6083

Dai WJ, Waldvogel A, Jungi T, Stettler M, Gottstein B (2003) Inducible nitric oxide synthase-deficiency in mice increases resistance to chronic infection with Echinococcus multilocularis. Immunology 10:238-244

Davies C, Goose J (1981) Killing of newly excysted juveniles of Fasciola hepatica in sensitized rats. Parasite Immunol 3:81-96

Devouge M, Ali-Khan Z (1983) Intraperitoneal murine alveolar hydatidosis: relationship between the size of the larval cyst mass, immigrant inflammatory cells, splenomegaly and thymus involution. Tropenmed Parasitol 34:15-20

Eger A, Kirch A, Manfras B, Kern P, Schulz-Key H, Soboslay PT (2003) Pro-inflammatory (IL-1beta, IL-18) cytokines and IL-8 chemokine release by PBMC in response to Echinococcus multilocularis metacestode vesicles. Parasite Immunol 25:103-105

Emery I, Liance M, Deriaud E, Vuitton DA, Houin R, Leclerc C (1996) Characterization of T-cell immune responses of Echinococcus multilocularis-infected C57BL/6J mice. Parasite Immunol 18:463-472

Frosch PM, Frosch M, Pfister T, Schaad V, Bitter-Suermann D (1991) Cloning and characterization an immunodominant major surface antigen of Echinococcus multilocularis. Mol Biochem Parasitol 48:121-130

Gottstein B (1992) Echinococcus multilocularis infection: Immunology and immunodiagnosis. Adv Parasitol 31:321-380

Gottstein B, Hemphill A (1997) Immunopathology of echinococcosis. Chem Immunol 66:177-208

Gottstein B, Hemphill A (2008) Echinococcus multilocularis: The parasite-host interplay. Exp Parasitol 119:447-452

Gottstein B, Tsang VCW, Schantz PM (1986) Demonstration of species-specific and cross-reactive components of Taenia solium metacestode antigens. Am J Trop Med Hyg 35:308-313

Hemphill A, Gottstein B (1995) Immunology and morphology studies on the proliferation of in vitro cultivated Echinococcus multilocularis metacestodes. Parasitol Res 81:605-614

Hernandez A, Nieto A (1994) Induction of protective immunity against murine secondary hydatidosis. Parasite Immunol 16:537544 
Hubner MP, Manfras BJ, Margos MC, Eiffler D, Hoffmann WH, Schulz-Key H, Kern P, Soboslay PT (2006) Echinococcus multilocularis metacestodes modulate cellular cytokine and chemokine release by peripheral blood mononuclear cells in alveolar echinococcosis patients. Clin Exp Immunol 145:243251

Ingold K, Gottstein B, Hemphill A (1998) Identification of a novel laminated layer-associated protein in Echinococcus multilocularis metacestodes. Parasitology 116:363-372

Ingold K, Gottstein B, Hemphill A (2000) High molecular weight glycans are major structural elements associated with the laminated layer of in vitro cultivated Echinococcus multilocularis metacestodes. Int J Parasitol 30:207-214

Ito A, Schantz PM, Wilson JF (1995) Em18, a new serodiagnostic marker for differentiation of active and inactive cases of alveolar hydatid disease. Am J Trop Med Hyg 52:41-44

Kizaki T, Kobayashi S, Ogasawara K, Day NK, Good RA, Onoé K (1991) Immune suppression induced by protoscoleces of Echinococcus multilocularis in mice. Evidence for the presence of CD8dull suppressor cells in spleens of mice intraperitoneally infected with E. multilocularis. J Immunol 147:1659-1666

Laemmli UK (1970) Cleavage of structural proteins during the assembly of the head of bacteriophage T4. Nature 227:680-685

Lawton P, Hemphill A, Deplazes P, Gottstein B (1997) Sarciron ME Echinococcus multilocularis metacestodes: immunological and immunocytochemical analysis of the relationships between alkaline phosphatase and the Em2 antigen. Exp Parasitol $87: 142-149$

Machado ER, Ueta MT, Lourenço EV, Anibal FF, Sorgi CA, Soares EG, Roque-Barreira MC, Medeiros AI, Faccioli LH (2005) Leukotrienes play a role in the control of parasite burden in murine strongyloidiasis. J Immunol 175:3892-3899

Martin LB, Kita H, Leiferman KM, Gleich GJ (1996) Eosinophils in allergy: role in disease, degranulation, and cytokines. Int Arch Allergy Immunol 109:207-215

Mejri N, Gottstein B (2006) Intraperitoneal Echinococcus multilocularis infection in C57BL/6 mice affects CD40 and B7 costimulator expression on peritoneal macrophages and impairs peritoneal T cell activation. Parasite Immunol 28:373-385

Mishra A, Hogan SP, Lee JJ, Foster PS, Rothenberg ME (1999) Fundamental signals that regulate eosinophil homing to the gastrointestinal tract. J Clin Invest 103:1719-1727

Mishra A, Hogan SP, Brandt EB, Wagner N, Crossman MW, Foster PS, Rothenberg ME (2002) Enterocyte expression of the eotaxin and interleukin-5 transgenes induces compartmentalized dysregulation of eosinophil trafficking. J Biol Chem 277:4406-4412
Muller N, Vogel M, Gottstein B, Scholle A, Seebeck T (1989) Plasmid vector for overproduction and export of recombinant protein in Escherichia coli: efficient one-step purification of a recombinant antigen from Echinococcus multilocularis (Cestoda). Gene 75:329-334

Ovington KS, Behm CA (1997) The enigmatic eosinophil: investigation of the biological role of eosinophils in parasitic helminth infection. Mem Inst Oswaldo Cruz 2:93-104

Persat F, Vincent C, Schmitt D, Mojon M (1996) Inhibition of human peripheral blood mononuclear cell proliferative response by glycosphingolipids from metacestodes of Echinococcus multilocularis. Infect Immun 64:3682-3687

Saraswathi TR, Nalinkumar S, Ranganathan K, Umadevi R, Elizabeth J (2003) Eosinophils in health and disease. J Oral Maxillofac Pathol 7:31-33

Sato C, Furuya K (1994) Isolation and characterization of a diagnostic polysaccharide antigen from larval Echinococcus multilocularis. Jpn J Med Sci Biol 47:65-71

Siles-Lucas Mdel M, Gottstein B (2003) The 14-3-3 protein: a key molecule in parasites as in other organisms. Trends Parasitol 19:575-581

Sterla S, Sato H, Nieto A (1999) Echinococcus granulosus human infection stimulates low avidity anticarbohydrate IgG2 and high avidity antipeptide IgG4 antibodies. Parasite Immunol 21:27-34

Terrazas LI, Walsh KL, Piskorska D, McGuire E, Harn DA (2001) The schistosome oligosaccharide lacto- $\mathrm{N}$-neotetraose expands $\mathrm{Gr}^{+}$cells that secrete anti-inflammatory cytokines and inhibit proliferation of naive $\mathrm{CD}^{+}$cells: a potential mechanism for immune polarization in helminth infections. J Immunol 167:5294-5303

Vuitton DA, Bresson-Hadni S, Laroche L, Kaiserlian D, GuerretStocker S, Bresson JL, Gillet M (1989) Cellular immune response in Echinococcus multilocularis infection in humans. II. Natural killer cell activity and cell subpopulations in the blood and in the periparasitic granuloma of patients with alveolar echinococcosis. Clin Exp Immunol 78:67-74

Walker M, Baz A, Dematteis S, Stettler M, Gottstein B, Schaller J, Hemphill A (2004) Isolation and characterization of a secretory component of Echinococcus multilocularis metacestodes potentially involved in modulating the host-parasite interface. Infect Immun 72:527-536

Yamaguchi Y, Hayashi Y, Sugama Y, Miura Y, Kasahara T, Kitamura S, Torisu M, Mita S, Tominaga A, Takatsu K (1988) Highly purified murine interleukin 5 (IL-5) stimulates eosinophil function and prolongs in vitro survival. IL-5 as an eosinophil chemotactic factor. J Exp Med 167:1737-1742 